\title{
PSYCHIATRIC STIGMA: TWO STUDIES OF BEHAVIOUR WHEN THE CHIPS ARE DOWN
}

\author{
STEWART PAGE \\ University of Windsor
}

\begin{abstract}
Ever since the research of Goffman (1961) the lot of the former mental patient has been of special import. Unfortunately, several aftereffects of mental hospitalization may occur, in which the disposition of the general public toward the ex-patient may be prejudiced, and, possibly, discriminatory. Except for that of Farina and colleagues, relatively little research has studied these aftereffects. Using a method developed by Page (1977), the present studies investigated a unique aspect of these, namely, problems experienced in obtaining accommodation. Persons identified as former patients experienced significantly greater difficulty in obtaining accommodation that when no such information was given. Comparisons are made with other types of stigma, involving speech impediments, and results are discussed in light of recent work by Farina and others.
\end{abstract}

Ever since the classic research of Goffman (1961), in which the negative properties of mental hospitalization were described, attention has been drawn to various problems experienced by the ex-patient in society. One of these effects concerns the social stigma placed by society upon the exmental patient who is attempting to reestablish himself in some fashion. Several studies, using case history, questionnaire, and rating scale procedures, have documented this stigma, at least when this type of abstract task is used. There is also evidence (e.g. Page 1980; Rosenhan, 1973) that even mental health professionals tend to view mental patients unfavourably, and sometimes behave differently toward them than toward "normal" persons.

The actual behaviour of the public toward ex-mental patients, however, has not been researched as thoroughly as have its responses to abstract tasks. Farina and Felner (1973) studied the reactions of interviewers, at 32 manufacturing concerns, to a confederate job applicant. From analyses of surreptitiously-made sound recordings of the interviewers, Farina and Felner found that when the confederate alleged a background involving mental illness, interviewer behaviour was rated as less friendly, and the applicant's chances of employment were described as less favourable. Still, the applicant in this condition was offered two jobs, while in the non-mental illness condition the applicant was offered four jobs. Interviewer behaviour was not uniformly friendly, or unfriendly, to the "mentally ill" applicant. In another study, Farina, Felner, and Boudreau (1973) found, in two studies, that department store workers evaluated a female co-worker (confederate) unfavourably when she showed obvious anxiety, but believing the confederate had been mentally ill did not affect such evaluations. (It did for male confederates however.) These results were noted by Farina et al. as somewhat surprising, in that they do not coincide with what is generally believed about behaviour toward the ex-patient. Still other studies, including one in which 429 former patients were interviewed (Gove \& Fain, 1973) and one involving an extensive (questionnaire) 
survey of public attitudes (Crocetti, Spiro, \& Siassi, 1974), found results consistent with the position that former patients are treated equitably by the general public. Crocetti et al. even claim that psychiatric stigma is now virtually nonexistent, and need not be a concern for the ex-patient.

While the above studies have been valuable in trying to assess stigmatization, it is necessary to study further the actual behaviour of the general public, and, further, to do so using a nonreactive measure such as the type initiated by Farina and colleagues.

Of primary import to many discharged mental patients is the problem of finding accommodation. This problem may even supercede that of finding employment, especially when the orientation of many mental hospitals is becoming that of discharging patients as soon as possible, and of community-based treatment programs. If the above view of Crocetti et al. is correct, the former patient should not experience significant difficulty in securing accommodation. Aside from its theoretical interest in the issue of psychiatric stigma, however, the need for accommodation is also a practical problem of great salience for the former patient.

Using a method of measuring community acceptance of stigmatized individuals (Page, 1977) the present study investigated the reactions of 150 members of the general public (landlords) to requests from ostensible former mental patients attempting to find accommodation (rooms or flats for rent). Comparisons were also made between the acceptance of former patients and that of persons with other types of stigma. The latter involved similar requests made for accommodation, in which the caller did not mention mental illness but did speak with obvious speech impediments, as described below.

\section{STUDY 1}

\section{Method}

Subjects. Subjects in study 1 were all contacted by telephone, following the procedure of Page (1977). These were 150 individuals, resident in Toronto, Ont., who had advertised rooms, or flats, for rent in either of the two major Toronto newspapers, i.e., the Star and the Globe \& Mail. Using telephone exchanges, an attempt was made to contact landlords living in different geographical areas of the city. Only landlords who included telphone numbers directly in their advertisements were selected. No landlord was called more than once. In order to maximize availability of rooms, all calls were placed in the morning, using the latest available edition of the two newspapers.

\section{Procedure}

Over a three-month period, 150 calls were made to landlords assigned randomly to one of three experimental conditions. In one condition, the caller (a female) alleged to be presently living in a mental hospital but looking for accommodation. In a second condition, the caller did not imply mental illness, but simulated a speech impediment in making enquiry about the room. A third, control, condition was also used (see below). In the "mental illness" condition $(\mathrm{N}=50)$, the caller stated, either verbatim or in close paraphrase: "Yes, my name is Jan Miner. I should tell you that $I$ am a patient now in a mental hospital, but I'm going to leave in a day or two, and $\mathrm{I} \mathrm{m}$ calling to see if your room (flat) is still for rent or not." If the response was negative, the caller said "thank you" and ended the call. If the response was positive, the caller said "OK, thank you, I'll call you back later," and ended the call.

In the second (speech impediment) condition $(\mathrm{N}=50)$, the caller followed the above procedure, but spoke with an unmistakeable stutter, accompanied by numerous filled pauses, such as "um" and "ah." These calls thus reiterated the enquiry about the room, but were awkward in terms of the caller's nonfluency. 
In a control condition $(\mathrm{N}=50)$, the caller made a simple enquiry as to availability of the room, without speech impediment or reference to mental illness.

All landlords' responses were recorded and later categorized as positive, negative, or "unsure". The latter category referred to instances in which the landlord did not appear clearly willing or unwilling to rent the room, such as when the caller was asked qualifying questions, e.g., "Are you quiet?" or "Are you French?", etc. Advertisements stipulating "businessman only," "Italian language only," etc., were not used.
As in Page (1977), the assumption that the rooms or flats were not already rented was checked further by making 18 additional calls, following the format of the control condition. In only one case was the room already rented.

Also, calls were timed, from the point of the initial enquiry until termination.

\section{Results}

The main results, i.e., the number of positive and negative responses obtained in the various conditions, are presented in Table 1 .

\section{Table 1}

Landlord Responses To Telephone Requests $(\mathrm{N}=150)$

$\begin{array}{lrrrc} & \text { Positive } & \text { Negative } & \text { Unsure } & \text { n } \\ \text { Control } & 45(90) & 2(4) & 3(6) & 50 \\ \text { Speech Impediment } & 33(66) & 15(30) & 2(4) & 50 \\ \text { "Mental Illness" } & 30(60) & 12(24) & 8(16) & 50\end{array}$

()$=\%$

When reference to mental illness was made, or when the speech impediment was present, rooms were unlikely to be deemed available. Forty-five $(90 \%)$ of calls in the control condition elicited positive responses, whereas the mental illness and speech impediment conditions elicited only $33(66 \%)$ and $30(60 \%)$ respectively.

A significant association was obtained between type of call and the likelihood of receiving a positive response, $\mathrm{x}^{2}(2)=12.31$, p<.01.

A significant relationship occurred between positiveness and absence of reference to mental illness, $x^{2}(1)=6.23, p, .001$. Also, there was a significant relationship between positiveness and absence of the speech impediment, $x^{2}(1)=12.49,<.001$.

No significant difference appeared be- tween the mental illness and speech conditions, $x^{2}(1)=.05$, NS. One-way analyses of variance, for both positive and negative responses indicated that neither the speech impediment, nor the mental illness condition, affected significantly the time taken by landlords to "accept" or "reject" the caller.

\section{Discussion}

On the average, the caller was about 50 per cent more likely to be told that a room was available if no reference was made to mental illness or hospitalization. Similar results were obtained by Page (1977), who also found that the mental illness label decreased room availability just as markedly as did an implied criminal label. The present results indicated however that the landlord 
sample also discriminated against the caller under conditions of speech nonfluency. The view (e.g., Goffman, 1961; Sheff, 1974) that "deviant" aspects of one's personality or social behaviour may result in subtle social stigmatization thus appears supported by these results. It might have been reasonably predicted that a stutterer would not elicit discrimination, in view of the presumed acceptance afforded such persons it has been assumed by many, if not all, professionals that former mental patients are also accepted by society in a humanitarian fashion. The present results do not support this view.

It would be difficult, in fact, to find subjects today who would knowingly indicate unaccepting responses toward the mental illness concept in interview, questionnaire, or social distance measures, in which the effects of social desirability and demand characteristics (Weitz, 1972; Orne, 1973) are likely to be considerable. Of import for the ex-patient, of course, is what the public does, aside from what it says. The present results indicate that the former patient stands a good chance of rejection, at least when the behaviour of the rejecting person can be studied nonreactively. When such measures are used, even individuals with nonpsychiatric medical, or pseudomedical, problems (such as stuttering) may be afforded incomplete acceptance.

Since study 1 was somewhat exploratory, a second study was undertaken to assess whether landlords would reject callers differentially, depending on the stigmatizing feature presented.

\section{STUDY 2}

In study 2 , an additional type of stigma was used, as described below.

\section{Method}

Subjects. Subjects were again tele- phoned, as in study 1 . These were 321 landlords, resident in Toronto, who had advertised rooms or flats, as before. None of this sample had been contacted in study 1 .

\section{Procedure}

In study 2,321 calls were placed to landlords assigned randomly to one of six experimental groups. Three manipulations were used: presence or absence of the mental illness label, presence or absence of stuttering (speech impediment) and presence or absence of a dissonant voice, as described below (see Table 2).

In three groups, the caller referred to mental illness, as in study 1 , and enquired as to availability of the room or flat. In one such group, she spoke fluently. In another, she stuttered. In another, she spoke with a dissonant, nasal tone, accomplished by pressing the nostrils together during speech. The voice was otherwise "natural."

In three additional groups, the caller again varied her speech fluency as in the above groups, but did not refer to mental illness, i.e., residence in the mental hospital.

Responses were recorded and categorized, as in study 1 . An additional check on availability of the rooms was again made, by placing 20 more control calls; in only 2 cases were rooms described as unavailable.

Duration of calls was again measured in all groups, except the two in which the dissonant voice was used, since the caller had inadvertently neglected to carry out the timing in these latter groups.

\section{Results and Discussion}

The main results, i.e., the number of positive and negative responses obtained in the various groups are presented in Table 2 . 
Table 2

Positive and Negative Landlord Responses

in Six Experimental Groups $(\mathrm{N}=321)$

Mental Illness Label

\section{Group \\ 1. Fluent \\ 2. Speech Impediment \\ 3. Dissonant Voice}

No Mental Illness Label
Positive Negative Unsure n

$30(56)$

$21(41)$

$22(43)$

19 (35)

$23(45)$

5 ( 9 )

54

$29(57)$

7 (14)

$0(0)$

Positive Negative Unsure n

Group

4. Fluent

$45(82)$

$40(71)$

8 (14)

2 ( 4)

55

5. Speech Impediment

$41(76)$

$14(25)$

2 ( 4$)$

13 (24)

$0(0)$

56

54

Results were similar to those of study 1 , and of Page (1977). The highest acceptance rate $(82 \%)$ occurred in the group with no mental illness reference, nor either type of speech nonfluency. Lowest rates of acceptance, and highest rates of rejection, were found with calls involving reference to mental illness and either the speech impediment or dissonant voice.

Frequency of positive responses was significantly decreased by reference to mental illness, $x^{2}(1)=25.61, p<001$.

Also, although the speech impediment and dissonant voice manipulations did not affect landlord responses differentially, the frequency data (Table 2 ) indicated that discriminatory behaviour was significantly more likely when either type of nonfluency was present than when the caller's voice was fluent, $x^{2}(1)=4.46, p<.05$. No significant relationship, in terms of acceptance rate, was found between the mental illness and the speech nonfluency manipulations, $x^{2}(1)$ $=.01$, NS.

Since these analyses necessarily involved nominal data, we could not examine possible interactions between the mental illness and nonfluency variables. A $2 \times 2$ (label $\times$ stuttering) analysis of variance of the call duration data, for calls from which positive responses were obtained, was not significant. However, for negative landlord responses, a $2 \times 2$ analysis of variance yielded a significant interaction between presence of the mental illness label and use of the speech impediment (stuttering) manipulation, $F(1,28)=4.52, p<.05$. The landlords thus rejected the fluent caller faster when she used the mental illness label (mean length $=9.0 \mathrm{sec}$.) than when she did not $($ mean length $=13.9 \mathrm{sec}$.). A test for simple effects showed, however, that when the caller was nonfluent, she was rejected significantly less quickly when the mental 
illness label was used (mean length $=32.8$ $\mathrm{sec}$.) than when the label was not used (mean length $=5.9 \mathrm{sec}$.), $\mathrm{t}(14)=3.01 \mathrm{p}$. .05. This suggests that effects of different stigmatizing features can be interactive, and that perhaps the present landlord sample experienced comparatively greater hesitation, and possibly guilt, in dealing with (and eventually rejecting) a mentally ill person with the additional stigma of a speech impediment. An additional chi-square test of association between frequency of landlord acceptance of the nonfluent caller, and presence or absence of the mental illness label, was in fact significant, $x^{2}(1)=7.0, p<.01$.

The present results confirm and extend those of study 1 . When calls referred to mental illness, what one might call discriminatory behavior occurred. It would appear that the actual acceptance of these persons in the real world may be less than what questionnaire measures (e.g., Crocetti, et al., 1974), for example, might predict. That such might be true of a sample of landlords, particularly, is perhaps doubly disappointing. It should be noted also that our caller, in both studies, was female. In view of evidence that females are thought to have been somewhat better accepted as ex-patients than males (Farina, 1981) the results may even more striking.

Again, there occurred discrimination against persons with speech difficulties, quite apart from considerations of mental illness. It could be hypothesized, then, that the public, if given a "safe" opportunity to do so, will tend to reject a person who is seen as deviant or different, largely inde- pendent of the particular stigmatizing condition involved. Such an opportunity would be any one in which the rejection may occur with little or no visibility, i.e., with low fear of detection, and in which the rejecting person attempts, perhaps understandably, to reduce or avoid the various "costs" of dealing with a stigmatized person.

The ex-patient should probably avoid deliberate or pointed reference to mental illness in employment or accommodationseeking situations. He also, in some cases, would profit from "self-presentation" training, for example, in terms of speech or appearance. But perhaps he should also avoid impersonal enquiries, for example, those made by letter, through second parties, or by telephone, particularly if reference to past mental illness or hospitalization occurs in the process, since these situations often allow low-visibility, "nonpublic" responses from employers, etc., whose content is often not verifiable or detectable. If this perspective is valid, then efforts to eliminate psychiatric stigma through increased education of the public, and to convince it that mental illness is a true sickness, etc., will not be as effective as will efforts to portray the former patient as a wronged minority-group member, similar to the black or homosexual. The acceptance and lot of such persons in the community may thus be increased when visible (and thus socially evaluable) responses are required from "normal" others, and also when there exist appropriate role models whose conduct portrays "proper," accepting, behavior toward minority groups.

\section{RÉSUMÉ}

Depuis la recherche de Goffman (1961), on a accordé une importance spéciale au sort de l'ex-patient psychiatrique. Après I'hospitalisation, plusieurs effets peuvent malheureusement survenir dont une attitude de la population à l'égard de l'ex-patient se traduisant par des préjugés, et possiblement, par de la discrimination. A part Farina et ses collaborateurs. relativement peu de chercheurs ont étudié les effets post-hospitalisation. tilisant une méthode développée par Page (1977), les études présentées 
ici explorent un aspect unique de ces effets, notamment les problèmes rencontrés pour obtenir certains services (restauration, logement, etc). Les personnes qui son identifiées comme anciens patients psychiatriques ont significativement plus de difficultés à obtenir ces services que lorsque cette information n'est pas donnée. On fait la comparaison avec d'autres types de traces ("stigma") impliquant les difficultés de langage et on discute des résultats à la lumière d'un ouvrage récent de Farina et ses collaborateurs.

\section{REFERENCES}

Crocetti, G., Spiro, H. \& Siassi, I. Contemporary attitudes toward mental health. Pittsburgh: University of Pittsburgh Press, 1974.

Farina, A. Are women nicer than men: Sex and the stigma of mental disorders. Clinical Psychology Review, 1981, in press.

Farina, A., \& Feiner, R. Employment interviewer reactions to former mental patients, Journal of Abnormal Psychology, 1973, 82, 268-272.

Farina, A., Felner, R., \& Baudreau, L. Reactions of workers to male and female mental patient job applicants. Journal of Consulting and Clinical Psychology, 1973, 41, 363-372.

Goffman, E. Asylums. New York: Doubleday \& Co., 1961.

Gove, W., \& Fain, T. The stigma of mental hospitalization. Archives of General Psychiatry, 1973. 28, 500 .

Orne, M. Communication by the total experimental situation: why it is important, how it is evaluated, and its significance for the ecological validity of findings. In P. Pliner, T. Krames, \& T. Alloway (Eds.), Communication and Affect, New York: Academic Press, 1973, 157-191.

Page, S. Effects of the mental illness label in attempts to obtain accommodation. Canadian Journal of Behavioural Science, 1977, 9, 85-90.

Page, S. Social responsiveness toward mental patients: the general public and others, Canadian Journal of Psychiatry, 1980, 25, 242-246.

Rosenhan, D. On being sane in insane places. Science, $1973,179,365-369$.

Scheff, T, The labeling theory of mental illness. American Sociological Review, 1974, 39. 444452.

Weitz, S. Attitude, voice, and behavior: A repressed affect model of interracial interaction. Journal of Personality and Social Psychology, 1972. 24. 14-21.

\section{FOOTNOTES}

Thanks are due to Miss Allyson Hamel-Smith and Miss Brenda Cowley, for performing this work. 